\title{
Administration Time-Dependent Change in the Effect of Spironolactone in Rats
}

\author{
Tsuyoshi Shiga, Akio Fujimura* and Akio Ebihara \\ Department of Clinical Pharmacology, Jichi Medical School, Minamikawachi-machi, Kawachi-gun, Tochigi 329-04, Japan \\ Received December 2, $1993 \quad$ Accepted March 25, 1994
}

\begin{abstract}
The present study was undertaken to examine whether the natriuretic effect of spironolactone, a competitive antagonist of mineralocorticoid, varies with its time of administration. Wistar rat maintained under the condition of light from $7 \mathrm{hr}$ to $19 \mathrm{hr}$ were divided into two groups. The first group had a bilateral adrenalectomy and received a 50-mg deoxycorticosterone acetate (DOCA) tablet intraperitoneally (DOCA group). The second group had a sham operation (control group). Spironolactone $(50 \mathrm{mg} / \mathrm{kg}$ ) was given orally at $12 \mathrm{hr}$ or $24 \mathrm{hr}$, and the 8-hr urine was collected. At the end of the experiment, the blood sample for measurement of aldosterone was obtained at $12 \mathrm{hr}$ and $24 \mathrm{hr}$ in the control group. The natriuretic effect of spironolactone in the $24 \mathrm{hr}$-trial was significantly greater than that of the $12 \mathrm{hr}$-trial in the control group. However, such a time-dependent difference was diminished and did not reach statistical significance in the DOCA group. The plasma aldosterone concentration at $24 \mathrm{hr}$ was significantly higher than that at 12 $\mathrm{hr}$ in the control group. These results suggest that the natriuretic effect of spironolactone varies with its time of administration. Daily variation in mineralocorticoid activity might be involved in this chronopharmacological phenomenon of spironolactone.
\end{abstract}

Keywords: Spironolactone, Aldosterone, Competitive antagonist, Natriuresis, Chronopharmacology

Spironolactone is a competitive antagonist of mineralocorticoids, of which aldosterone is the most potent endogenous hormone, and produces a natriuresis (1). The level of an endogenous hormone might influence the effect of its competitive antagonist. For example, the hypotensive effects of competitive angiotensin II-receptor antagonists, saralasin and losartan, are influenced by plasma angiotensin II concentrations; and their hypotensive responses are greater when plasma angiotensin II concentrations are higher $(2,3)$. As the plasma aldosterone concentration shows a typical daily variation with a peak during the night-time and a nadir during the daytime in rats (4), it is suspected that the natriuretic effect of spironolactone is greater when it is administered in the night-time than when it is administered in the daytime in these nocturnal animals. To examine this hypothesis, spironolactone was given orally at $12 \mathrm{hr}$ or $24 \mathrm{hr}$ in rats. The natriuretic response in the 24 -hr trial was compared with that of the 12-hr trial.

\footnotetext{
* To whom correspondence should be addressed.
}

\section{MATERIALS AND METHODS}

Male Wistar rats [specific pathogen free (SPF) animal] (Charles River Laboratory, Kanagawa) weighing 300 to $350 \mathrm{~g}$ were maintained for more than 4 weeks under conditions of light (approximately $50 \mathrm{lux}$ ) from $7 \mathrm{hr}$ to $19 \mathrm{hr}$ and dark from $19 \mathrm{hr}$ to $7 \mathrm{hr}$ with free access to food (MF; Oriental Yeast Co., Ltd., Tokyo) and water. The animals were housed and the following experiments were performed in an SPF room. This study was carried out during winter (January and February in 1993).

In study I (pre-operation study), 3\% body weight (b.w.) of $1 \% \mathrm{NaCl}$ solution was given by gavage into the stomach at $12 \mathrm{hr}$ (or $24 \mathrm{hr}$ ). Twenty-four hours after $\mathrm{NaCl}$ solution alone, $50 \mathrm{mg} / \mathrm{kg}$ of spironolactone (Sigma, St. Louis, MO, USA) in $3 \%$ b.w. of $1 \% \mathrm{NaCl}$ solution was given orally at $12 \mathrm{hr}$ (or $24 \mathrm{hr}$ ). Urine was collected for $8 \mathrm{hr}$ by using a metabolic cage (Immortal; Okazaki Sangyo (o., Ltd., Tokyo) following $\mathrm{NaCl}$ solution alone or the drug administration at $12 \mathrm{hr}$ (or $24 \mathrm{hr}$ ). Food and water were withdrawn for $8 \mathrm{hr}$ after each administration. The administration of the drug was randomly assigned to $12 \mathrm{hr}$ or $24 \mathrm{hr}$. The washout period between the two sets 
of experiments was 3 days. Thereafter, these rats were randomly divided into two groups. The first group of rats [deoxycorticosterone acetate (DOCA) group, $n=12$ ] was subjected to bilateral adrenalectomy and received a 50-mg DOCA tablet intraperitoneally under pentobarbital anesthesia. Sham operation was performed on the second group of animals (control group, $n=12$ ). Ten days after the operation, the identical protocol for study I was repeated (study II, post-operation study). Seven days after the final dosage of spironolactone, blood samples were obtained under pentobarbital anesthesia at $12 \mathrm{hr}(\mathrm{n}=6)$ and $24 \mathrm{hr}(\mathrm{n}=6)$ in the control group of rats.

Urinary concentrations of sodium and potassium were determined by an autoanalyzer (Model 736; Hitachi, Tokyo). Plasma aldosterone was measured by radioimmunoassay (5).

The results are expressed as the mean \pm S.E. Data were analyzed by analysis of variance.

This experiment was performed in accordance with the Jichi Medical School Guide for Laboratory Animals.
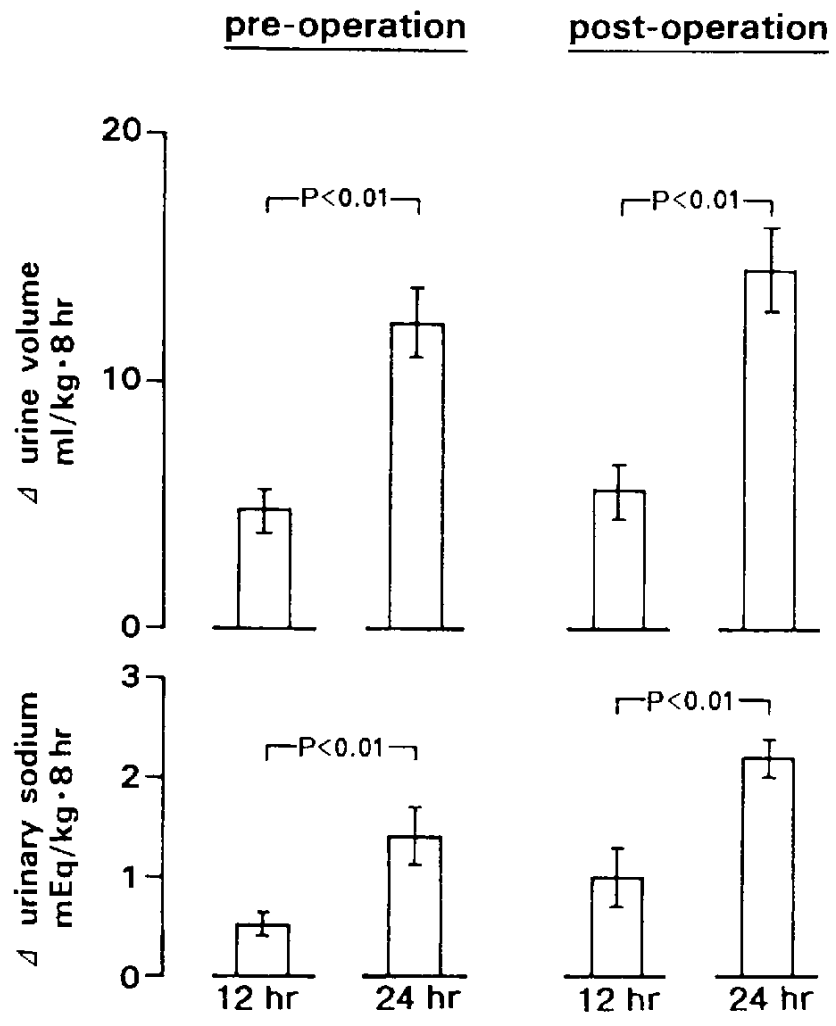

Administration time

Fig. 1. Increments in urine volume ( $\Delta$ urine volume) and urinary sodium ( $\Delta$ urinary sodium) after administration of spironolactone $(50 \mathrm{mg} / \mathrm{kg}$ ) at $12 \mathrm{hr}$ or $24 \mathrm{hr}$ in the control group of rats. mean \pm S.E. $n=12$.

\section{RESULTS}

Urine volume and urinary sodium excretion increased significantly $(P<0.01)$ following spironolactone in both groups. In the control group, the increments in these parameters $[\Delta$ urine volume $(\Delta$ urinary sodium $)=$ urine volume (urinary sodium) following spironolactone urine volume (urinary sodium) following $\mathrm{NaCl}$ solution alone] in the $24-\mathrm{hr}$ trial were significantly greater than those of the 12-hr trial in the pre-operation and post-operation studies (Fig. 1). In the DOCA group, the $\Delta$ urine volume and $\Delta$ urinary sodium were also greater in the 24 $\mathrm{hr}$ trial than in the 12-hr trial of the pre-operation study (Fig. 2). The values of these parameters in the post-operation study were significantly greater than those of the preoperation study in the 12-hr trial, but not in the 24-hr one. Consequently, the administration time-dependent differences in the $\Delta$ urine volume and $\Delta$ urinary sodium were diminished and did not reach statistical significance in the post-operation study (Fig. 2). 
Table 1. Urinary $\mathrm{Na}: \mathrm{K}$ ratio in the control and DOCA groups

\begin{tabular}{ccc}
\hline & Pre-operation & Post-operation \\
\cline { 2 - 3 } & $12 \mathrm{hr}$-trial $24 \mathrm{hr}$-trial & $12 \mathrm{hr}$-trial $24 \mathrm{hr}$-trial \\
\hline & $-\mathrm{P}<0.01-$ & $\mathrm{P}<0.01-$ \\
Control group & $2.3 \pm 0.1 \quad 1.8 \pm 0.1$ & $2.6 \pm 0.1 \quad 2.0 \pm 0.1$ \\
& $-\mathrm{P}<0.05-$ & \\
DOCA group & $2.0 \pm \mathbf{0 . 1} \quad 1.6 \pm 0.1$ & $2.1 \pm 0.1 \quad 1.9 \pm 0.1$ \\
\hline
\end{tabular}

Three percent b.w. of $1 \% \mathrm{NaCl}$ solution was given orally at $12 \mathrm{hr}$ or $24 \mathrm{hr}$, and the 8-hr urine was collected. mean \pm S.E. $n=12$.

Table 2. Plasma concentration of aldosterone in the control group of rats

\begin{tabular}{lcc}
\hline & \multicolumn{2}{c}{ Sampling time } \\
\cline { 2 - 3 } & $12 \mathrm{hr}$ & $24 \mathrm{hr}$ \\
\hline Plasma aldosterone $(\mathrm{ng} / \mathrm{dl})$ & $8.3 \pm 0.4$ & \multicolumn{2}{c}{$12.2 \pm 0.05$} \\
\hline
\end{tabular}

mean \pm S.E. $n=6$.

Urinary $\mathrm{Na}: \mathrm{K}$ ratio following $\mathrm{NaCl}$ solution alone in the 24-hr trial was significantly lower than that of the 12 hr trial in the pre-operation study of both groups and in the post-operation study of the control group (Table 1). However, such an administration time-dependent difference was not observed in the post-operation study of the DOCA group (Table 1). Plasma aldosterone concentration was significantly higher at $24 \mathrm{hr}$ than at $12 \mathrm{hr}$ in the control group (Table 2).

\section{DISCUSSION}

The urinary $\mathrm{Na}: \mathrm{K}$ ratio serves as an indirect index of endogenous mineralocorticoid activity, and the decreased ratio shows the increased mineralocorticoid activity (1). In the control group, the urinary $\mathrm{Na}: \mathrm{K}$ ratio following $\mathrm{NaCl}$ solution alone in the 24-hr trial was significantly lower than that of the 12-hr trial in the present study. In addition, the plasma concentration of aldosterone, the most potent mineralocorticoid, was significantly higher at $24 \mathrm{hr}$ than at $12 \mathrm{hr}$. These results suggest that the mineralocorticoid activity was higher during the 24-hr trial than during the 12-hr trial in the control group. On the other hand, the urinary $\mathrm{Na}: \mathrm{K}$ ratio of the $12-\mathrm{hr}$ and $24-\mathrm{hr}$ trials did not differ significantly in the DOCA group. This finding suggests that the level of the mineralocorticoid activity during the 24-hr trial was similar to that of the 12-hr trial in the DOCA group.

Effect of a competitive antagonist might be enhanced when the level of the endogenous hormone is higher (2,
3). It is well known that plasma concentrations of mineralocorticoids are higher during the night-time than during the daytime in rats (4). As spironolactone is a competitive antagonist of mineralocorticoid, it is suspected that the effect of the agent varies with its time of administration, and the spironolactone-induced natriuresis is greater when it is administered at night-time than when it is administered at daytime in rats. The present finding that the natriuretic effect of spironolactone in the 24-hr trial was significantly greater than that of the 12 -hr trial is compatible with this hypothesis. The present study also showed that such an administration time-dependent difference was diminished in the DOCA group. This was probably caused by the reduced daily variation in mineralocorticoid activity in these animals.

In summary, the present study showed that the effect of spironolactone varied with its time of administration. Daily variation in mineralocorticoid activity might be involved in this chronopharmacological phenomenon of spironolactone. However, the following possibility can not be ruled out: Absorption of several agents from the gastrointestinal tract is faster when they are given orally during an active period (night-time in rats), which in turn leads to higher plasma concentrations and enhanced pharmacologic effects (6). Further studies involving measurements of plasma concentrations of spironolactone and its active metabolite canrenone are needed to evaluate the mechanism of this event in more detail.

\section{REFERENCES}

1 Weiner, IM: Diuretics and other agents employed in the mobilization of edema fluid. In The Pharmacological Basis of Therapeutics, 8th edition, Edited by Goodman Gilman A, Rall TW, Nies AS and Taylor P, pp 713-731, Pergamon Press, New York (1990)

2 Thananopavarn C, Golub MS, Eggena P, Barrett JD and Sambhi MP: Angiotensin II, plasma renin and sodium depletion as determinants of blood pressure response to saralasin in essential hypertension. Circulation 61, 920-924 (1980)

3 Smith RD, Chiu AT, Wong PC, Herblin WF and Timmermans PBMWM: Pharmacology of nonpeptide angiotensin II receptor antagonists. Annu Rev Pharmacol Toxicol 32, 135-165 (1992)

4 Gomez-Sanchez C, Holland OB, Higgins JR, Kem DC and Kaplan NM: Circadian rhythms of serum renin activity and serum corticosterone, prolactin, and aldosterone concentrations in the male rat on normal and low-sodium diet. Endocrinology 99, 567-572 (1976)

5 Vecsei P, Abdelhamid S, Mittelstaedt GV, Lichtwald K, Haack $\mathrm{D}$ and Lewicka S: Aldosterone metabolites and possible aldosterone precursors in hypertension. J Steroid Biochem 19, $345-351(1983)$

6 Labrecque $\mathrm{G}$ and Bélanger PM: Biological rhythms in the absorption, distribution, metabolism and excretion of drugs. Pharmacol Ther 52, 95-107 (1991) 